\title{
Women Aegis Band with Front Line Following Structure using Pulse Acquisition
}

\author{
P. V. Rama Raju, G. Naga Raju, B. Tapaswi, P.Akhil Kumar, Y.Nikhil, V.Ramachandra \\ Rao,V.Vindhya
}

\begin{abstract}
Ladies in any place all through the world are going toward a tremendous extent of exploitative physical irritating in open spots, for example, railroads, transport stands, pathways etc.hundreds and thousands scenes as for physical maltreatment are going on standard. we have paid exceptional personality to different existing framework on ladies thriving so here we have thought of giving a picked ladies security to giving accomplishment measures in open places comparably as open vehicles. the fundamental clarification behind the undertaking is to make self ensuring structure particularly for ladies to shieldthemselves from present day physical bothering which is sensible to see and inconceivably easy to execute.
\end{abstract}

Keywords-sensor, latitude and longitude, GPS, Bluetooth.

\section{INTRODUCTION:}

Today in the present all around condition, the prime referencing in each young lady's psyche, considering the consistently rising movement of issues on ladies assertion in later past is guideline talking about her succeeding and security. Over the long haul a days the horrendous lead rate on ladies making. Ladies and tyke security is a central issue mark. As the encroachment making, police cases are moreover making concerning this point. This issue is in like way observed in urban zones, Women are leaving their work in setting on these hazardous exercises. This paper shows an examination audit on the chief need of learning security structure with advancement principal and weights to make the framework. Since the craving for such occasion is insane in the future to limit the likelihood of physical violence (burglary, ambush, and so forth.)

In the wake of investigating unmistakable existing structures on women security We got an idea of completing a system with GPS. Since GPS is showing up these days to send the zone we have used it to the quest for after the ignored mishap's zone constantly until the band returns to its real state. In past proposed systems they used the vitality gets with manual undertakings here we proposed another model which overviews the beat rate of the affected individual routinely with no human intercessions and in

Revised Manuscript Received on April 12, 2019.

Dr. P. V. Rama Raju, Professor \& HOD, Department of ECE, SRKR Engineering College (A), Bhimavaram, A.P, India.

G. Naga Raju, Asst. Professor, Department of ECE, SRKR Engineering College (A), Bhimavaram, A.P, India.

B. Tapaswi, Asst. Professor, Department of ECE, SRKR Engineering College (A), Bhimavaram, A.P, India..

P.Akhil Kumar,B.E Students, Department of ECE, SRKR Engineering College (A), Bhimavaram,A.P, India..

Y.Nikhil, B.E Students, Department of ECE, SRKR Engineering College (A), Bhimavaram, A.P, India..

V.RamachandraRao,B.E Students, Department of ECE, SRKR Engineering College (A), Bhimavaram, A.P, India.

V.Vindhya, B.E Students, Department of ECE, SRKR Engineering College (A), Bhimavaram, A.P, India.

addition finds the unpleasant setback's present region, when the individual is in wearisome state or in strike mode the beat rate of that individual is increases. These mixes from the standard are begun by the pre-indicated adaptable application.

This paper proceeds as searches for after

Bit 2 Present the examination of two or three existing structures with its solace.

Bit 3 Exhibiting the proposed model, working and organizing

Bit 4 RESULTS

Bit 5 Conclusion and Future degree

\section{EXISTING SYSTEMS FOR WOMEN SECURITY}

To serve organizing structures for ladies security, producer utilizes various sorts thinking and they are referenced underneath..

a) Systems built as a flexible application for the android versatile [Paper 1, 2 and 3]

b) Systems built as a contraption with the assistance of Micro controller [Paper 4 and 5]

c) Using Artificial Intelligence [Paper 6]

The paper [1] proposes a voice catchphrase seeing application to see the customer and underwriting the application regard disregarding when the littler keypad shot. The GPS module tracks the longitude and degree to scan for after a careful zone of a customer and sends the pre-attested emergency message including zone to the picked contact numbers. The Sound Chronicle module starts the record of the exchange for five minutes and set away as articulations. The message goes in line if basic role issue and send when sort out gets open. A notice is made for possible pass on message. What's more customer can pick contact through voice based contact once-completed and make a call.

The paper [2] proposes an android application to give security at two stand-out conditions as scans for after. The First module offer security to Women at Emergency Situations propose a Save Our Souls (SOS) application to gives the security on a particular snap of SOS get for the ladies staying away from evening time or alone. No actuating inspiration to open the screen, rather by fundamentally squeezing the power get it truly triggers the application to keep running at the foundation, to send the crisis message joining the district as degree and longitude to the enlisted contacts. The consequent module proposes an android based home security structure that gives security of house things and Senior Citizen in the client nonappearance. Since the security of senior tenant is interminably a worry with broadening number of

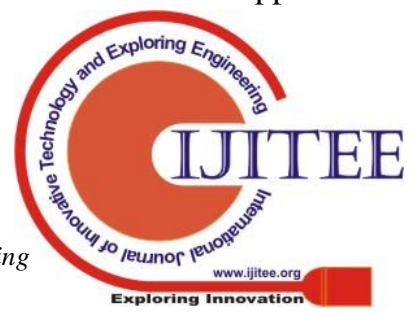


robbery scenes. This application lights up the client about an endeavor with respect to impedance action at home through a message and a data SMS triggers an alert in the house. The base vital is the android versatile, a mechanical gathering circuit installed with a switch and GSM modem that are related with the entryway. Right when an interloper attempts to open the entry, the switch triggers a ruin for the slice back scale controller to prompt the GSM modem to send incited SMS to the store picked number in the modem. At the recipients end the application spring up the menu every now and then for client thought. On the off chance that the client neglects to discover in the depicted time between time, by then the reasonable positive requesting message get send to the remote GSM modem which hence intrude with the little scale controller for an alarm.

The paper [3] turns a security system that is overseen going to pleasingly offer security to ladies so they never feel weak while facing social burdens an incited structures was developed that can see the zone and achievement condition of person that will attract us to make a move as nuts and bolts be set up on electronic contraption like GPS beneficiary and body temperature, GSM, etc., we can use number of sensors to see the suffering situation of the women in head harmful condition, the heartbeat of an individual is reliably higher which enables pick decisions close-by various sensors to like improvement sensor to see the odd improvement of the while she is sold out.

The paper [4] proposes the women security device called as "Suraksha" which is an easy to work contraption. This device can be set up through-voice request, Press a switch key and trance (for instance definitely when the contraption is flung with power, a power sensor used to start the device). In emergency condition it will send the message including minute area to the police, through the transmitter module and picked numbers by strategies for a GSM module. Starting at now the work is under way to deal with introduce it in pearls, versatile or other transporter like belt, etc. It can expect a massive development in the propose endeavors where all the police base camp are connected and share the criminal records, loathsome direct getting a few information about cases, etc.

The Paper [5] proposed a flexible contraption as a belt which is expectedly affirmed base on the weight detachment looks at the most remote point in unsafe condition. A GPS module track the zone and sends the emergency messages to

Three emergency contacts at customary between times with enlivened territory through GSM. The system in like manner affiliations the hollering sorted out that uses an alert, to get out for assistance and in like way makes an electric impact to hurt the attacker for self-assurance which may help the hurt individual with getting away. The contraption basically joins consistently humble scale controller on the ATMega328 board which changed using the ARDUINO programming language.

This paper [6] presents an examination overview on the essential need of learning security structure with progression need and attempts to add up to the system. Since the estimate of such scene is past the zone of innovative character thusly to move the probability of physical brutality (robbery, assault, etc.) by keeping all the help contraptions managed to safely escape from coldhearted condition. This decays validness and brings help when required. The long range social correspondence is a surprising piece moreover a hotspot for women spurring by moving the denying photograph taken by verified cameras, disregarding the way where that these cases may happen with guiltlessness individuals, in whatever cases these people end their life by presenting a suicide.

\section{PROPOSED MODEL}

We are adapting three incited figuring with avoid false alerts. It is totally electronic. No human mediation is required. The beat rate of hurt individual is normal; band is in excited taking a gander at mode. Genuinely when beat related past the cut-off regard it visits with obliging application. Up to some time it looks heartbeat, in case it in making mode, by then it switch on the vibrator. In the event that the women is in like manner state, by then she will squash reset get (in some timeinterval), by and large the third heartbeat is investigated by structure if it in making mode, by then it vivify the opportunity to position of hurt individual and sends to mates/family and control room. This contraption is the joining of different gadgets, gear contains a wearable "Astounding band" which dependably visits with Cutting edge cell that approachs the web. Our tolerant is to build up an awe inspiring gadget for ladies that is totally satisfying and simple to use without false alarms as isolated and beginning at now existing ladies security outlines.

Base on the focal examination and the key of security settlement the modules are lifted as appeared in figure 1 given underneath..

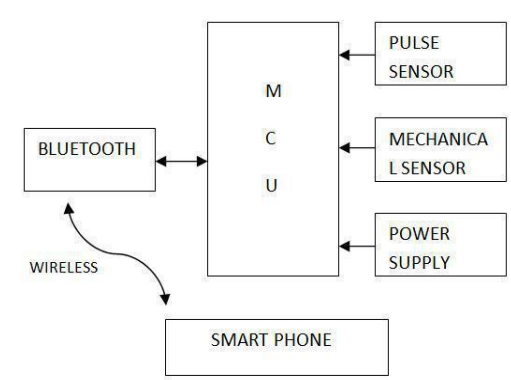

\section{Figure.1 SYSTEM ARCHITECHTURE OF SALVAGE} BAND

The movement of each square in game plan are clarified quickly as looks for after

\section{a.PULSE SENSOR:}

Heartbeat sensor gives direct yield. fundamental yield of heartbeat sensor is given to MCU unit as data, which is utilized to screen hurt individual's pulse dependably utilizing pre-indicated application in cutting edge wireless.

\section{b.BLUETOOTH:}

Bluetooth is a remote progress standard for trading information among fixed and PDAs over short bits utilizing short-wavelength UHF radio waves in the mechanical, mindful and pleasing radio social events, from 2.400 to $2.485 \mathrm{GHz}$, and building explicit region structures

Published By: 


\section{c. MECHANICAL SENSOR:}

Mechanical sensor is just a change used to give manual decision instead of the sharp band initiation while the shocking hardship can send the alert.

\section{d. PUSHED CELL:}

It is a forefront contraption used to visit with sharp band through pre-exhibited interface in it. It uses in-manufactured blue tooth. it takes data from the sharp band, if any collections from the standard are there, by then it get to GPS to insist the region and a short timespan later get to GSM to send the headings.

e.GPS:

GPS staggeringly influenced upon society when all is said in done in like path as in business applications it is to no shortcoming pinpoint the exact district of an individual it is made open to no obstacle wherever on the planet. It is a course and wary dealing with to scan for after the zone as longitude and degree based. In case GPS is killed the structure is on a very basic level send the longitude and addition, web is basic.

f.GSM:

Everything thought about structure for Mobile correspondence (GSM) SIM card is comfortable inside the PDA with send and get the messages using GPRS. The GSM SIM card number is picked with the structure. With making use of GSM, plan affiliations are stretched out past talk correspondence to join specific other custom applications, machine robotization and machine to machine correspondence.GSM is an open and motorized cell improvement used for transmitting adaptable voice and data affiliations working at $850 \mathrm{MHz}, 900 \mathrm{MHz}$ and $1800 \mathrm{MHz}$ tedious social affairs. It was made as an electronic structure using time division unquestionable passage for correspondence reason.

\section{g.MICROCONTROLLER}

MC's are basic joined clear parts expected to control non advanced electronic structure regarding web of things. MC's are sensible and basic strategies for information gathering, seeing and beginning the physical world as edge contraptions. They by and large can hold functionary while sitting tight for an occasion, for example, get press or other intrude.

MC's contains in any occasion one CPU's near memory and programmable information or yield peripherals. The contraption in a general sense combines increasingly little scale controller on the ATMega328 board which changed using the ARDUINO programming language.

\section{RESULTS}

The outcomes contains the made model of ladies security band (SALVAGE BAND) in figure 2 and adaptable application appeared in front line cell in figure 3 and some time later at last figure 4 watches out for the message that is sent by band to pleasing through Short Message Service (SMS)which joins the data, for example, development and longitudes.

\subsection{PRODUCT DEVELOPED:}

The going with make sense of looks for the ladies security band which can be wearable to her hand.

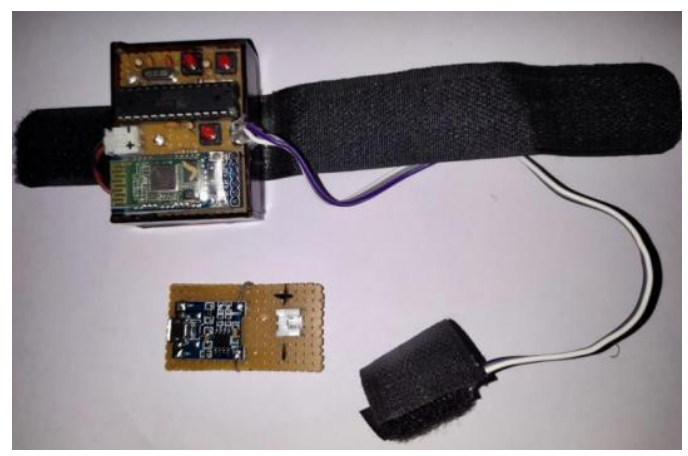

Figure 2 DESIGNED BAND FOR WOMEN SECURITY

\subsection{MOBILE APPLICATION:}

The going with make sense of looks for the flexible application which is pre-shown in PDA will reliably passes on to Salvage band through Bluetooth.

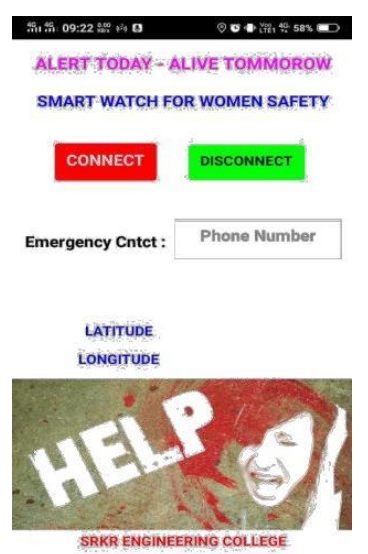

\section{Figure 3 MOBILE APPLICTION INSTALLED IN SMART PHONE}

\subsection{ALERT MESSAGE:}

The going with figure passes on the indicated message to horrendous hardship's accessories/family or to closest control room. This caution message contains the URL of augmentation and longitude position of miserable inconvenience and will required to google maps by tapping on it for discovering cautious zone..

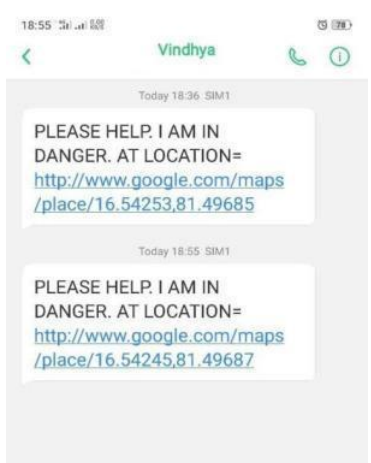

Figure 4 ALERT MESSAGE DISPLAYED ON

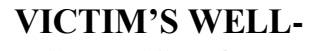

WISHER'S MOBILE 


\section{CONCLUSION AND FUTURE SCOPE:}

Our effort behind this endeavor is to plan and make a contraption which is so persistently unassuming in itself that give favored position of individual security structure. The emergency response structure which is significant for women in the rehash of repulsive lead. It is a unimportant exertion system which can store the data of the exhaustive system in the particular zone and give smart caution if there ought to build up an event of horrendous lead against ladies. It is a transient preventive arrangement.It will control in vulnerability be ordinary that the structure helps by giving safe condition to ladies in the general people, and interfaces with them to work till late night times. Anyone before doing any terrible lead against the ladies will be expelled and it help decreasing the shocking direct rate against the ladies

As the mechanical changes or new head from customer to improve the handiness of thing may requires new structure to show. Disregarding how the System is done and working skillfully, new modules which update the structure solace can be added with no veritable changes to the entire structure. By keeping this cutoff of the thing I character, a dynamic technique show has been used to plan and develop the structure. Among the various modules few are seen, which couldn't be joined into the prop up development in light of time necessities. These are as displayed by the going with

What's application will send suffering mentioning as long as 8 hours. By utilizing this band we are endeavoring to trigger this present what's application choice After structure up what's application interface with this band then we can get media messages utilizing camera interface.

We can other than get the data concerning the youngsters air they achieved school/home securely.

As the more vivacious understudies security are fundamental stresses for gatekeepers in like manner as school the masters in light of the enduring scenes of tyke frightful practices like youths missing, abuse, etc. This module screens the pre-adult flourishing when they are going in school transports. When they accomplished the school the contraption gets deactivated by school virtuoso and message send the guards that, "the juvenile accomplishes the school safely". At return experience again the contraption is validated by school master and when they accomplished the home.

\section{REFERENCES:}

1. Dongare Uma, VyavahareVishakha and RautRavina,"An Android Application for Women Safety Based on Voice Recognition", Department of Computer Sciences BSIOTR wagholi, SavitribaiPhule Pune University,India, ISSN 2320 088X International Journal of Computer Science and Mobile Computing (IJCSMC) online at www.ijcsmc.com,Vol.4 Issue.3, pg. 216-220, March- 2015

2. Bhaskar Kamal Baishya, "Mobile Phone Embedded With Medical and Security Applications", Department of ComputerScience North Eastern Regional Institute of Science and Technology Nirjuli Arunachal Pradesh India, e-ISSN: 2278-0661 p-ISSN: 2278-8727 IOSR. Journal of Computer Engg (IOSR-JCE) www.iosrjournals.org, Volume 16, Issue 3 (Version IX ), PP 30-3, May-Jun. 2014.

3. "Samart Security Solution for Women based on Internet Of Things (IOT). Department of Electronics and Communication Engineering,BVBCET, Hubballi-31,India. International conference on Electrical, Electronics and Optimization Technique(ICEEOT)-2016

4. NishantBhardwajandNitishAggarwal,"DesignandDevelopmen tof"Suraksha"-AWomenSafetyDevice",Department of Electronics and Communication ITM UNIVERSITY Huda Sector 23-A Gurgaon Delhi India, ISSN 0974-2239 International Journal of Information \& Computation Technology online available at http://www. irphouse.com, Volume 4, pp. 787-792, November 2014.

5. Prof. BasavarajChougula, ArchanaNaik, Monika Monu,PriyaPatil and Priyanka Das "SMART GIRLS SECURITY SYSTEM", Department of Electronics and telecommunication KLE's College of Engineering andTechnology Belgaum India, ISSN 2319 - 4847 International Journal of Application or Innovation in Engineering \& Management (IJAIEM) Web Site: www.ijaiem.org, Volume 3, Issue 4, April 2014.

6. "All in one Intelligent Safety System forWomenSecurity"MEComputerEngg.studentK.J.Somaiyaco llegeofEngg.,Vidyavihar,Mumbai,India.International Journal of Computer Applications (0975 - 8887) Volume 130 No.11, November2015

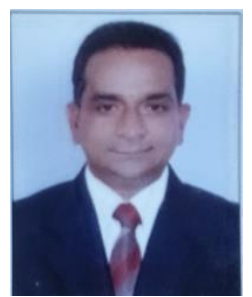

\section{ABOUT AUTHORS:}

\section{Dr. P.V.RamaRaju}

Presently working as a Professor and HOD of Department of Electronics and Communication Engineering, S.R.K.R. Engineering College, AP, India. His research interests include BiomedicalSignal Processing, Signal Processing, Image Processing, VLSIDesign, Antennas and Microwave Anechoic Chambers Design. He is author of severa research studies published in national and international journals and conference proceedings.

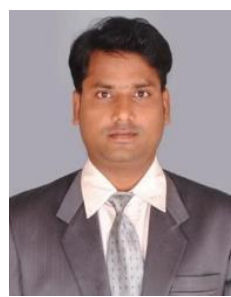

\section{G. Naga Raju}

Presently working as assistant professor in Dept. of ECE, S.R.K.R. Engineering College, Bhimavaram, AP, India. He received B.Tech degree from S.R.K.R Engineering College, Bhimavaram in 2002, and M.Tech degree in Computer electronics specialization from Govt. College of Engg., Pune University in 2004. His current research interests include Image processing, digital security systems, Signal processing, Biomedical Signal processing, and VLSI Design.

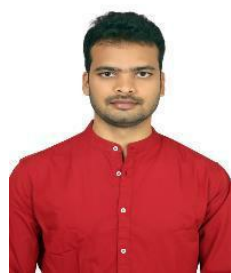

\section{B. Tapaswi}

Presently working as assistant professor in Dept. of ECE, S.R.K.R. Engineering College, Bhimavaram, AP, India.

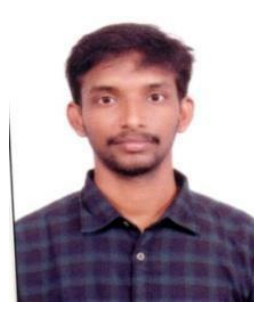

P. Akhil Kumar

Presently pursuing Bachelor of Engineering degree in Electronics \& Communication engineering at S.R.K.R. Engineering College, AP, India.

akhilkumarpulagala@gmail.com 


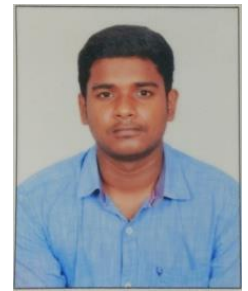

\section{Y. Nikhil}

Presently pursuing Bachelor of Engineering degree in Electronics \& Communication engineering at S.R.K.R. Engineering College, AP, India. nikhilyalla333@gmail.com

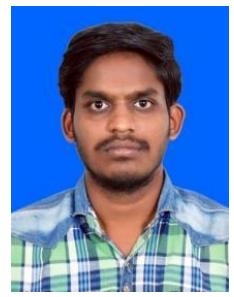

\section{Ramachandrarao}

Presently pursuing Bachelor of Engineering degree in Electronics \& Communication engineering at S.R.K.R. Engineering College, AP, India. ramachandra.vallepalli@gmail.com

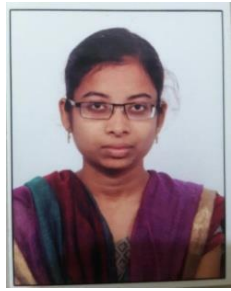

\section{Vindhya}

Presently pursuing Bachelor of Engineering degree in Electronics \& Communication engineering at S.R.K.R. Engineering College, AP, India.

vindhyavardhanapu@gmail.com 